\title{
US physicists greet promise of open access to CERN's hadron collider
}

Washington \& Munich. The European Laboratory for Particle Physics (CERN) in Geneva, Switzerland, and the US government have agreed to proceed with detailed negotiations on the participation of US scientists in the planned Large Hadron Collider (LHC) project on the basis of a US contribution of approximately $\$ 530$ million.

Officials continue to stress that the agreed figure is intended only as a basis for negotiation, and does not constitute a commitment of funds. But physicists on both sides of the Atlantic are jubilant at the news, which appears to open the way for the largest ever US involvement in a scientific facility built overseas.

The negotiations, which are due for completion by December, will proceed on the basis of contributions from the US Department of Energy (DOE) of about $\$ 225$ million for accelerator development and construction and about $\$ 225$ million for the particle detectors, in addition to $\$ 80$ million for the detectors from the National Science Foundation (NSF), according to a statement issued jointly last week by CERN and DOE.

The tentative agreement indicates that the two sides have overcome wide differences about the necessary scale of a US contribution (See Nature 379, 757; 1996). According to US officials, the DOE made its offer of $\$ 450$ million "plus or minus $\$ 50$ million" at talks in Washington DC with Hubert
Curien, the former French research minister who is president of the CERN Council, on 29 February. It was accepted at a meeting of the council two weeks later.

"We have reached a very significant midway point in the discussions with CERN," says Martha Krebs, director of the DOE's Office of Energy Research and leader of the US negotiating team. She adds that "the significant number is really the mid-point" - \$450 million - and that US scientists would get open access to the facility, with the thorny question of restricting access "not an issue" in the negotiations.

Christopher Llewellyn Smith, director general of CERN, says that he is "thrilled by the progress of the negotiations", as well as by what he describes as the "constructive attitude" of the DOE and NSF.

Sidney Drell, deputy director of the Stanford Linear Accelerator Center (SLAC) in California, and chair of an advisory panel of US physicists that two years ago recommended a DOE contribution of $\$ 400$ million to the LHC project, describes the news as "absolutely terrific".

Neal Lane, director of the NSF, says that the foundation's proposed contribution has still to be agreed by the its governing body, the National Science Board. It would also

\section{Scientists lose cold fusion libel case}

Munich. Stanley Pons and Martin Fleischmann have lost an 8-billion-lire (US\$6.3-million) libel case that they brought two years ago against an Italian journalist who referred to their work on 'cold fusion' as fraudulent.

The two scientists, who claimed to have achieved fusion of deuterium atoms at low temperatures while working at the University of Utah in Salt Lake City in 1989 , had objected to some colourful wording in a review in La Repubblica by Giovanni Pace of a book about scientific fraud by Axel Kahn, a prominent French geneticist, called False Prophets.

They sued the newspaper, and were joined in their legal action by three Italian scientists from the University of Milan, Giuliano Preparata, Tullio Bressani and Emilio Del Giudice. These were not mentioned by name, but believed that, as fellow advocates of cold fusion, they could be identified from the review (see Nature 363, 107; 1993)

But the judge ruled that Pace's words "represented an expression of the right to report and criticize on the part of the journalist, and as such are not derogatory", and ordered the five scientists to pay costs of L28.5 million. After hearing scientific evidence from experts representing both sides, the judge concluded that the claim by Fleischmann and Pons to have achieved cold fusion remained an unproven hypothesis.

He said that Pace's criticisms were justified "on the basis of the existence of important opposition from the scientific community, not just against the theory of the research and the way the experiments were conducted, but also the way the data were divulged and the conclusions reached about the future direction of research".
A. A.

\author{
IMAGE \\ UNAVAILABLE \\ FOR COPYRIGHT \\ REASONS
}

Now with added American acceleration? A computer graphic of the LHC in the existing LEP tunnel.

“take a big bite" out of NSF's annual \$54million budget for high-energy physics. But "CERN is going to be the most important place for high-energy physics, and it is extremely important that US scientists participate," Lane says.

US officials say that the numbers should be regarded as a basis for two negotiating groups, one dealing with the accelerator and the other with the detectors, to proceed with discussing the possible options, not as a firm US commitment.

That caution is echoed by Robert Walker (Republican, Pennsylvania), chair of the Science Committee in the US House of Representatives. The committee's strong support will be necessary - but not sufficient - to ensure funds for the project. A statement from Walker said he was "very supportive of US participation" in the LHC. But he did not endorse the suggested level of expenditure.

The White House Office of Science and Technology Policy (OSTP) has so far declined to comment, referring enquiries to DOE. But OSTP is said to be supportive of the negotiations, and - according to congressional staff - the low profile being adopted by the White House could help to keep the project out of trouble in Congress.

The Drell panel said that money for participating in the LHC could be taken from within the existing, \$670-million high-energy physics budget at DOE after 1998, when major construction projects at SLAC and at Fermilab in Illinois are due to be completed.

The DOE has requested $\$ 15$ million for LHC work in its 1997 budget, an increase from the $\$ 6$ million approved for this year. The largest part of the US contribution would be spent between 1999 and 2005, when the project is due for completion.

Colin Macilwain \& Alison Abbott 